\title{
Assessment of Heavy Metal Profile in Commercially Packaged Water in Ado Metropolis, Ekiti State, Nigeria
}

\author{
Oluwatuyi SHEGUN Victor \\ ${ }^{1}$ Kwara State University, Malete, Ilorin \\ Department of Environmental Health Science. \\ ${ }^{2}$ Ekiti State College of Health Sciences and Technology Ijero \\ Department of Public Health \\ Co-Authors: \\ Makanjuola Bosede Christianah, \\ Ekiti State College of Health \\ Sciences and Technology Ijero \\ Department of Environmental Health \\ Sam-Ijadele Oluwakemi Ifedayo, \\ Ekiti State College of Health \\ Sciences and Technology Ijero \\ Department of Environmental Health
}

Adewumi Michael Onasanmi,

Ekiti State College of Health

Sciences and Technology Ijero

Department of Environmental Health

\section{Bello Mojisola \\ Ekiti State College of Health Sciences and Technology Ijero Department of Environmental Health}

Abstract:- Commercially packaged water has been the main source of water supply to residents of Ado Metropolis; due to lack of potable water supply, individuals depend on commercial packaged water for drinking and domestic use. As a result of this, one has little or no assurance on the quality and safety of the water and its source. Heavy metal contamination includes exposure to lead, mercury, arsenic and cadmium, heavy metal contamination in Ado metropolis includes anthropogenic sources which includes activities of mining industries as discharge their untreated effluents into nearby water sources, other source of contamination includes automobile source that releases zinc, arsenic and copper; insecticides which releases arsenic and burning of fossil fuels which releases nickel, vanadium and mercury. Heavy metals cause general body weakness, abdominal pain, shortness of breath, chills, diarrhea, vomiting and tingling in the hands and feet when consumed. Hence, this study is important because it will reveal the presence of heavy metals in sampled waters in Ado Metropolis and also compare with WHO standard which in turn gives room for the suggestion of mitigating measures to regulate the sale of these public waters. Some brands of commercially packaged were purchased from different markets in Ado metropolis based on accessibility and high demands. The samples were coded as BW001,BW002,BW003,BW004for the bottled water samples while SW001,SW002,SW003,SW004 were used for sachet water samples,. The $\mathrm{pH}$ was determined and calculated by using the concentration of hydrogen ion and its concentration in the solution. The samples were treated with HNO3 and analyzed using Atomic Absorption Spectrophotometer to detect level of lead, mercury, chromium, nickel etc. The heavy metals showed they are within permissible limits except $\mathrm{Ni}$ and
Oluwatuyi Mayowa Funmilayo

Ekiti State College of Health Sciences and Technology Ijero Department of Health Information Management.

$\mathrm{Pb}$ in some of the samples. There are also evidence of the presence of chromium, lead, mercury, chromium and manganese though below WHO MPL. Some samples are within WHO MPL while some recorded high concentration of $\mathrm{Pb}$, and $\mathrm{Ni}$. Continual consumption of this water containing the trace level of heavy metals could result into heavy metal accumulation and magnification, affect food chain and causing diseases in human population in the nearest future.

Keywords:- WHO MPL, Trace metals, AAS, Effluent, Water treatment.

\section{INTRODUCTION}

Water is a universal solvent; it is a liquid substance that is needed in abundance by all living organisms for survival. Water is a compound that contains oxygen and hydrogen and it is a natural substance that contributes immensely to the existence of all life on Earth[5]. A wholesome water is odorless, colorless, tasteless, free from turbidity, not acidic nor contain any form of contaminants or pollutants. [18]. The consumption of unsafe water possess health threats to consumers, the risk of water related diseases and poisoning continue to become worrisome as long water sources are not safe. Water is a very essential component of our environment. Most of the diseases in developing countries are caused by the consumption of polluted water. Over one thirds of deaths in most developing countries are caused by water pollution. Water is necessary for the proper functioning of the human body. [28]. About $70 \%$ of the human body is made up of water. Potable water is good quality water that has neither smell nor odor and can be taken with no risk of harm[13] Water is a very important component of biochemical 
processes in the body. Drinking water should conform to standards set by the World Health Organization. Water is a life sustaining drink and it is essential for the survival of all organisms. It is a very important part of metabolic process and it is involved in most biological processes. The consumption of water containing toxic chemicals leads to damages in the human body[22]. The metals can accumulate in the human body and poses serious health risks to the people consuming such unwholesome water. Water can be rendered undrinkable if its physical qualities are undesirable. Due to this fact, the assessment of drinking water quality and its continuous monitoring are of utmost importance[18]. Most of the people living in developing countries lack access to clean water due to environmental pollution. It is the right of every individual to have access to safe drinking water. The presence of heavy metals in drinking water leads to many diseases in the human populace. Heavy metals are metals that have atomic weights of more than 40 . They include arsenic, cadmium, lead, mercury, etc. They do not easily break down once they are in the environment and they have toxic effects on plants and human beings. Chromium found in water is usually in the hexavalent form which is carcinogenic and highly toxic. Lead has no essential function in man and it can be found occurring as metallic lead, lead salts and lead inorganic ions[9]. Children are more sensitive to lead because of their rapid growth rate and metabolism. Cadmium is naturally present in the environment in soils, the air sediments and sea water. It is emitted into the air by industries using cadmium compounds for pigments, batteries, plastic alloys, etc. People are exposed to cadmium when consuming plant and animal based foods, together with sea foods. Cadmium accumulates in the human bodies and it affects the lungs, liver, kidney, brain central nervous system, etc. Other damages include hepatoxic toxicity, reproductive, hematological and immunological toxicities. The WHO guideline for cadmium in drinking water is $0.003 \mathrm{mg} / \mathrm{L}$. Trace metals in minute amounts are essential in the human body because of their involvement in many processes within the human bodies. At higher concentrations, they are associated with increased risks for diabetes, cancer, liver disease, heart disease, endocrine disease, etc. [23]. Trace metals leak into groundwater from natural and anthropogenic sources thereby rendering them undrinkable. One of the UN Millennium Development Goals is to reduce by half, the proportion of people without sustainable access to safe drinking water by the year 2015 . The UN convention on the Rights of the child stipulates that all children have the right to safe drinking water[17]. The presence of heavy metals or trace metals in water renders it unfit for consumption and use.

\section{MATERIALS AND METHODS}

\section{$>$ Study Population}

Presently there are over 12 bottle water company and 27 sachet water factory in Ado Metropolis with two Major markets and Ten major stores for wholesale and retail of sachet and bottle waters.

\section{Sampling}

Four different brands of commercially packaged were purchased from different markets in Ado metropolis based on accessibility and high demands. The samples were Tolu packad waters [BW001], Gossy water [BW002], Keye water [BW003] and Trios water [BW004] with four different brands of sachet water based and accessibility and high demands which are coded as Yemi pure water [SW001], Dele pure water [SW002], Folic sachet water [SW003] and Poly pure water [SW004].

\section{> PH Determination}

The pH of water sample SW001, SW002, SW003, SW004 and BW001, BW002, BW003, BW004 were subjected to $\mathrm{PH}$ testing with results analyzed below. The $\mathrm{pH}$ of an aqueous solution is the measure of how acid or basic it is. The $\mathrm{pH}$ was determined and calculated by using the concentration of hydrogen ion and its concentration in the solution.

\section{Sample Treatment}

The samples were treated with $\mathrm{HNO} 3$ to reduce $\mathrm{pH}$ and allow oxidation of the samples before AAS analysis. The metal ions are converted into nitrates because of their solubility before sample digestion which is done before AAS analysis.

\section{$>$ Heavy metal determination}

Acidification of the samples was done using nitric acid while allowing digestion to occur at temperature 100 degree Celsius until a clear solution was noticeable.

The solution was mixed with deionized water and filtered after which analysis of heavy metals was carried out using Atomic Absorption Spectroscopy which involves atoms absorbing radiations in gases.

\begin{tabular}{|c|c|}
\hline Step 1: $50 \mathrm{ml}$ mixed with $10 \mathrm{ml}$ of nitric acid & Step 2: Reduce mixture to 10ml \\
\hline Step 3: Use of volumetric flask of $50 \mathrm{ml}$ & Step4 : Dilute with ionized water and mix together \\
\hline Step 5: Ensure the mixture reaches $50 \mathrm{ml}$ & Step 6: Filter and analyze for heavy metals \\
\hline
\end{tabular}




\section{RESULTS}

BW- Bottle water samples

SW- Sachet water samples

\begin{tabular}{|c|c|c|}
\hline LABELLING & SAMPLE CODE & PH \\
\hline A & BW001 & $\mathbf{6 . 0 2}$ \\
\hline B & BW002 & $\mathbf{6 . 7 0}$ \\
\hline C & BW003 & $\mathbf{6 . 2 1}$ \\
\hline D & BW004 & $\mathbf{5 . 7 0}$ \\
\hline
\end{tabular}

Table 1:- shows PH of BW001-BW004

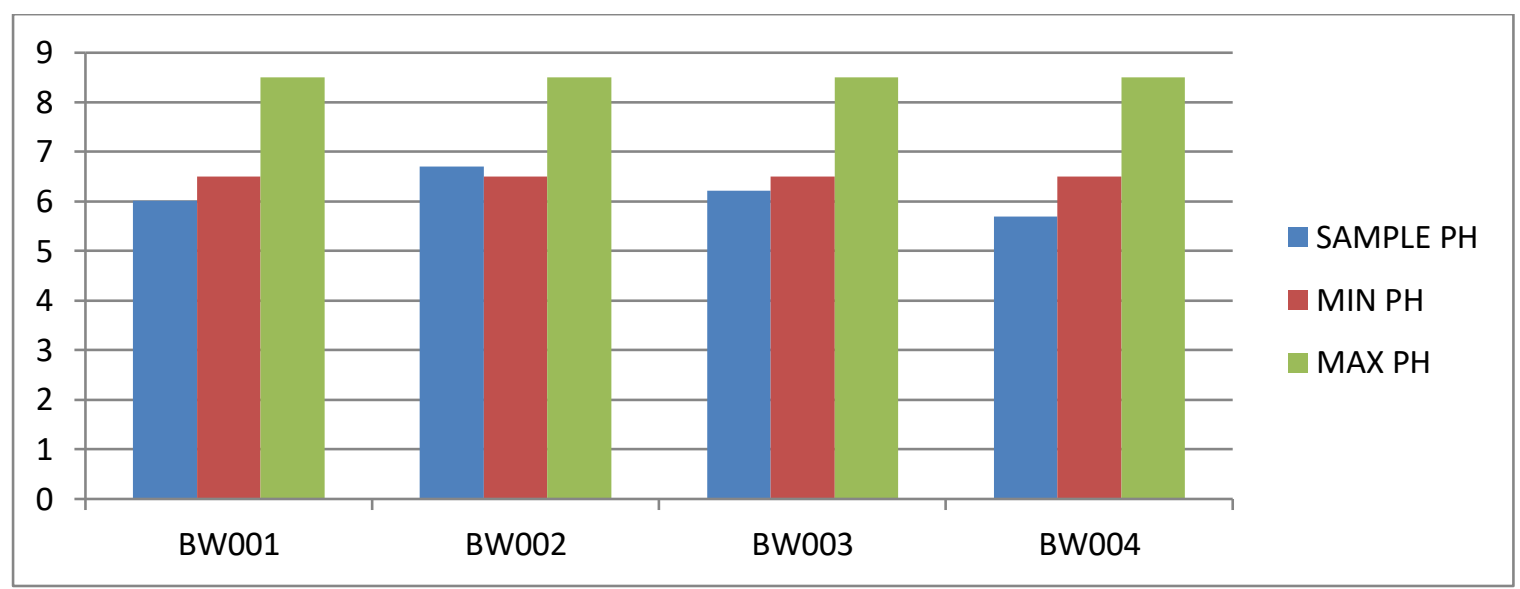

Fig 1:- showing pH of SW001-SW004

\begin{tabular}{|c|c|c|}
\hline LABELLING & SAMPLE CODE & PH \\
\hline A1 & SW001 & $\mathbf{6 . 6 0}$ \\
\hline A2 & SW002 & $\mathbf{6 . 8 6}$ \\
\hline A3 & SW003 & $\mathbf{6 . 8 1}$ \\
\hline A4 & SW004 & 6.92 \\
\hline
\end{tabular}

Table 2:- shows PH SW001-SW004

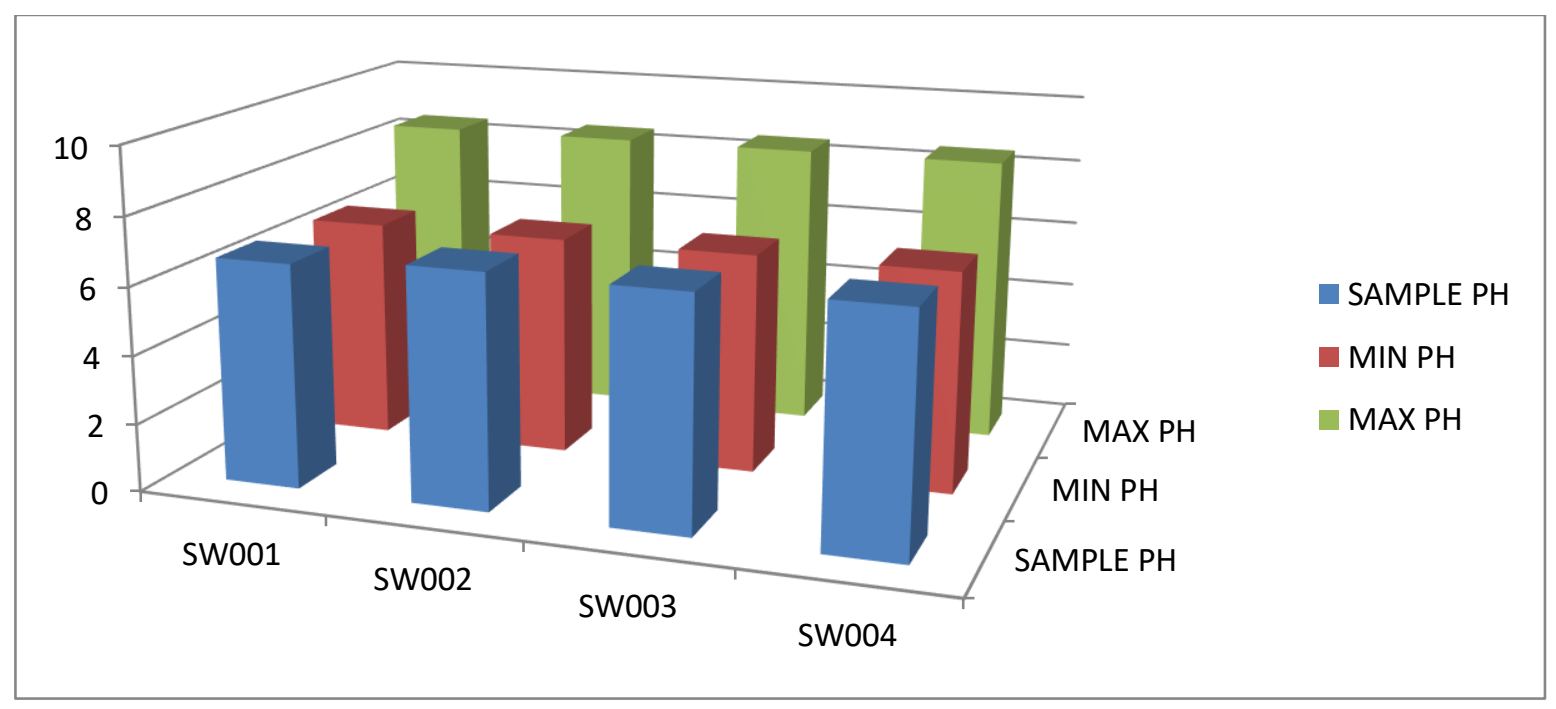

Fig 2:- showing PH of SW001-SW004 
ISSN No:-2456-2165

\begin{tabular}{|c|c|c|c|c|c|c|c|}
\hline LABELLING & $\begin{array}{c}\text { SAMPLE } \\
\text { CODE }\end{array}$ & Pb & Ni & Cd & Cr & Cu & Zn \\
\hline A1 & SW001 & $\mathbf{0 . 0 1} \pm \mathbf{0 . 0 2}$ & $\mathbf{0 . 0 1} \pm \mathbf{0 . 0 1}$ & $\mathbf{0 . 0 1} \pm \mathbf{0 . 0 1}$ & $\mathbf{0 . 0 1} \pm \mathbf{0 . 0 1}$ & $\mathbf{0 . 0 2} \pm \mathbf{0 . 0 1}$ & $\mathbf{0 . 5 3} \pm \mathbf{0 . 0 4}$ \\
\hline A2 & SW002 & $\mathbf{0 . 0 1} \mathbf{0 . 0 2}$ & $\mathbf{0 . 0 1} \mathbf{0 . 0 2}$ & ND & $\mathbf{0 . 0 1} \pm \mathbf{0 . 0 1}$ & $\mathbf{0 . 0 2} \pm \mathbf{0 . 0 1}$ & $\mathbf{1 . 0 0 \pm 0 . 1 0}$ \\
\hline A3 & SW003 & $\mathbf{0 . 0 1} \mathbf{0 . 0 1}$ & $\mathbf{0 . 0 1} \mathbf{0 . 0 1}$ & $\mathbf{0 . 0 1} \pm \mathbf{0 . 0 1}$ & $\mathbf{0 . 0 1} \mathbf{0 . 0 1}$ & $\mathbf{0 . 0 1} \pm \mathbf{0 . 0 1}$ & $\mathbf{1 . 3 2} \pm \mathbf{1 . 2 0}$ \\
\hline A4 & SW004 & ND & $\mathbf{0 . 0 1} \pm \mathbf{0 . 0 2}$ & $\mathbf{0 . 0 0 3}$ & $\mathbf{0 . 0 1} \pm \mathbf{0 . 0 2}$ & $\mathbf{0 . 0 3} \pm \mathbf{0 . 0 4}$ & $\mathbf{0 . 7 5} \pm \mathbf{0 . 0 5}$ \\
\hline WHO & & $\mathbf{0 . 0 1}$ & $\mathbf{0 . 0 2}$ & $\mathbf{0 . 0 0 3}$ & $\mathbf{0 . 0 5}$ & $\mathbf{2 . 0 0}$ & $\mathbf{3 . 0 0}$ \\
\hline
\end{tabular}

Table 3:- Heavy metals in SW001-SW004

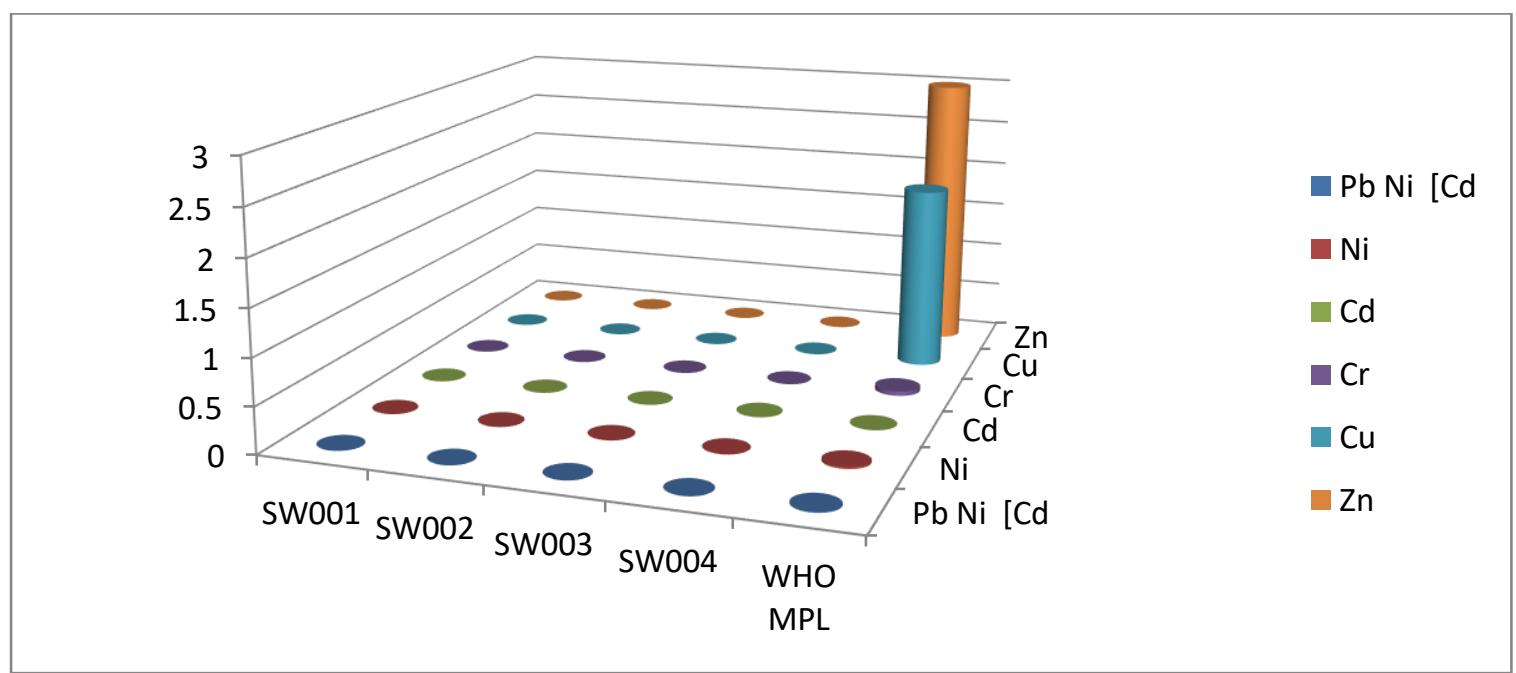

Fig 3:- Heavy metals in SW001-SW004

\begin{tabular}{|c|c|c|c|c|c|c|c|}
\hline LABELLING & $\begin{array}{l}\text { SAMPLE } \\
\text { CODE }\end{array}$ & $\mathbf{P b}$ & $\mathrm{Ni}$ & Cd & $\mathrm{Cr}$ & $\mathbf{C u}$ & $\mathbf{Z n}$ \\
\hline $\mathbf{A}$ & BW001 & $0.02 \pm 0.01$ & $0.02 \pm 0.02$ & ND & $0.01 \pm 0.01$ & $0.04 \pm 0.03$ & $0.80 \pm 0.99$ \\
\hline B & BW002 & $0.01+0.01$ & $0.01 \pm 0.02$ & $0.01+0.01$ & $0.01+0.01$ & $0.02+0.02$ & $1.47+0.89$ \\
\hline C & BW003 & $0.02 \pm 0.01$ & $0.01 \pm 0.01$ & ND & $0.02 \pm 0.01$ & $0.03 \pm 0.02$ & $0.68 \pm 0.49$ \\
\hline D & BW004 & $0.01 \pm 0.01$ & $0.01 \pm 0.02$ & ND & $0.01 \pm 0.01$ & $0.04 \pm 0.02$ & $0.18+0.43$ \\
\hline WHO & & 0.01 & 0.02 & 0.003 & 0.05 & 2.00 & 3.00 \\
\hline
\end{tabular}

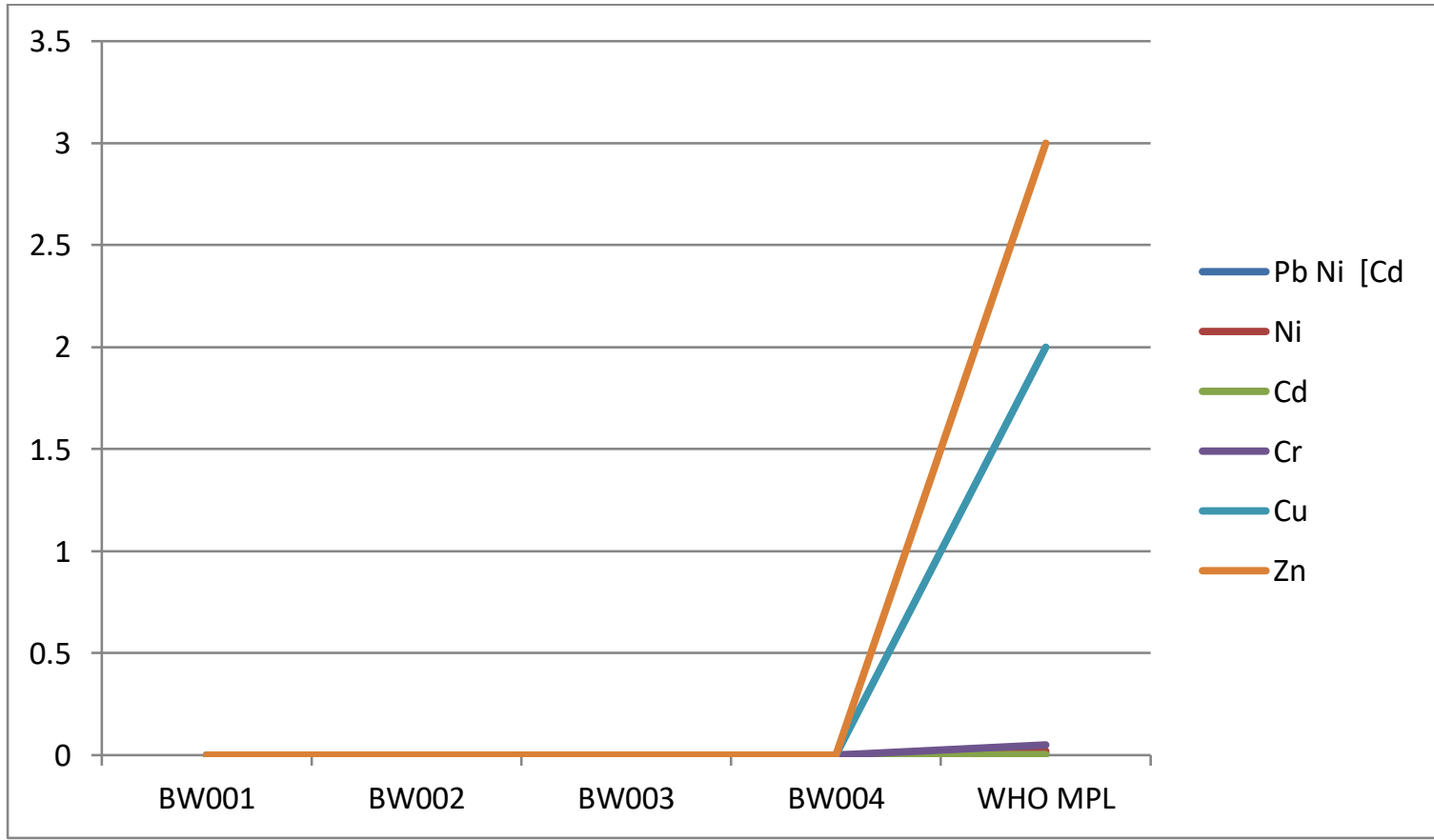

Fig 4:- Heavy metals in BW001-BW004 
ISSN No:-2456-2165

\begin{tabular}{|c|c|c|c|c|c|c|c|}
\hline LABELLING & $\begin{array}{l}\text { SAMPLE } \\
\text { CODE }\end{array}$ & $\mathbf{P b}$ & $\mathbf{N i}$ & $\mathbf{C d}$ & $\mathrm{Cr}$ & $\mathbf{C u}$ & $\mathbf{Z n}$ \\
\hline $\mathbf{A}$ & BW001 & $0.08 \pm 0.30$ & $0.60 \pm 0.22$ & $1.31 \pm 0.67$ & $0.14 \pm 0.10$ & $\begin{array}{c}100.25 \pm \\
17.11\end{array}$ & $2.95 \pm 1.22$ \\
\hline B & BW002 & $0.06 \pm 0.48$ & $0.05 \pm 0.08$ & $2.77 \pm 2.01$ & $0.58 \pm 0.32$ & $\begin{array}{c}100.55 \pm \\
14.55\end{array}$ & $0.95 \pm 1.26$ \\
\hline C & BW003 & $0.07 \pm 0.52$ & $0.07 \pm 0.20$ & $8.02 \pm 4.02$ & $0.80 \pm 0.61$ & $\begin{array}{c}126.22 \pm \\
12.11\end{array}$ & $4.34 \pm 2.16$ \\
\hline D & BW004 & $0.06 \pm 0.21$ & $0.08 \pm 0.12$ & $6.32 \pm 3.31$ & $1.61 \pm 1.01$ & $\begin{array}{c}92.11 \pm \\
13.12\end{array}$ & $1.30 \pm 1.10$ \\
\hline WHO & & 0.30 & 0.40 & 10.00 & 5.00 & 200.00 & 10.00 \\
\hline
\end{tabular}

Table 5:- Trace metals BW001-BW004

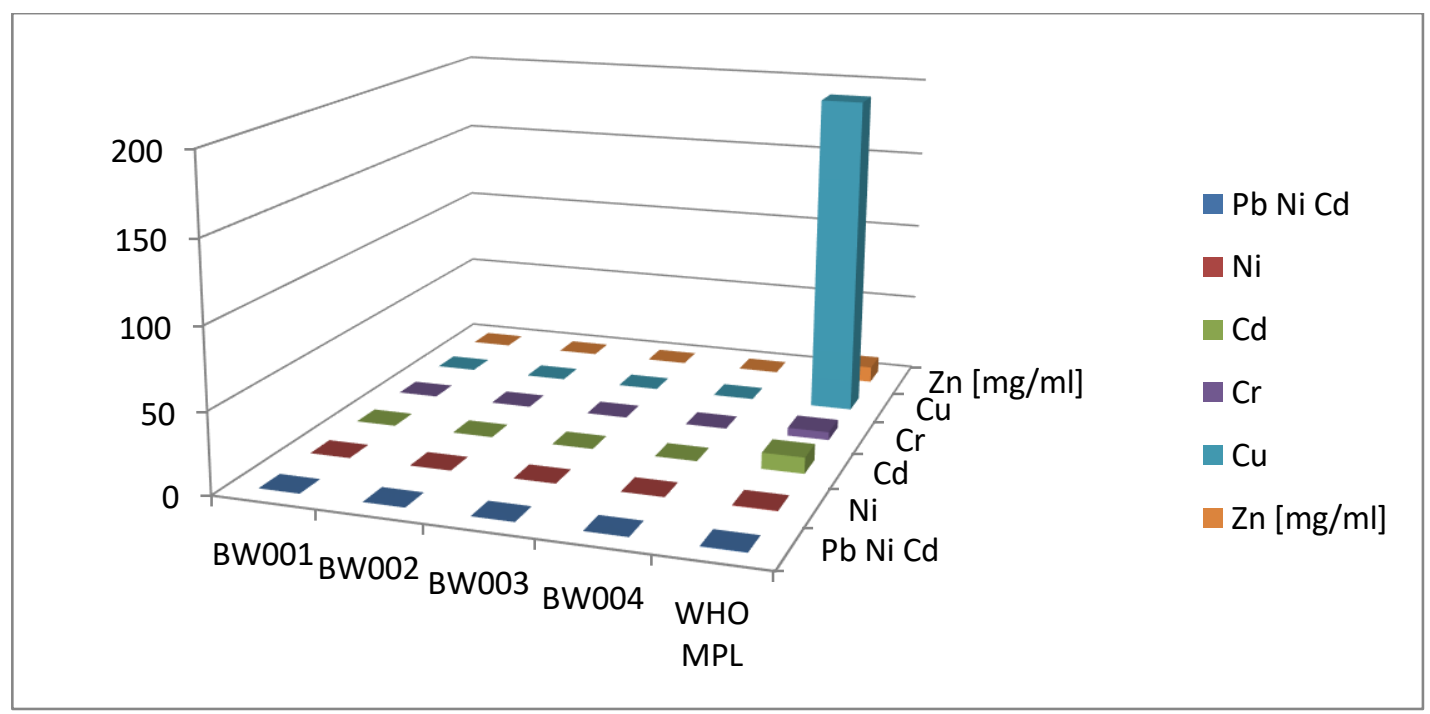

Fig 5:- Trace metals in BW001-BW004

\section{DISCUSSION}

Taking into the consideration the results analyzed in the above tables and using World health organization standard as correlation factors, the heavy metals showed they are within permissible limits except $\mathrm{Ni}$ and $\mathrm{Pb}$ in some of the samples. There are also evidence of the presence of chromium, lead, mercury, chromium and manganese though below WHO MPL. Some samples are within WHO MPL while some recorded high concentration of $\mathrm{Pb}$, and $\mathrm{Ni}$. Continual consumption of this water containing the trace level of heavy metals could result into heavy metal accumulation and magnification, affect food chain and causing diseases in human population in the nearest future.

\section{CONCLUSION}

Since access to potable and safe water is limited hence the reliance on commercially-packaged drinking water. Studies have shown that there are need to give utmost concern towards the regulation of the production and sale of commercially packaged water $[28,22,18,6]$. Quite a number of this commercially packaged water are processed without taking into consideration WHO MPL standards. There are however health indices and issues expressed about the safety of some of the seen commercially packaged water. Government agencies tasked with regulation of these commercially packaged water should be more proactive and ensure the water sources are subjected to rigorous sampling analysis, testing and treatment.

\section{REFERENCES}

[1]. WHO/UNICEF (2012): Estimated data from WHO/UNICEF Joint Monitoring Programme (JMP) for water supply and sanitation. Progress on sanitation and drinking water.

[2]. Zuthi MFR, Biswas M, Bahar MW (2009) Assessment of supply water quality in the Chaittagong Town of Bangladesh. ARPN Journal of Engineering and Applied Sciences 14.

[3]. Chang TJ, Ke DS, Guo HR (2010) The association between arsenic exposure from drinking water and cerebrovascular disease mortality in Taiwan. Water Res 44: 5770-5776.

[4]. WHO (2008) Guidelines for Drinking water quality. Third Edition. Incorporating the 1st and 2nd Agenda Volume Recommendations. World Health Organization, Geneva.

[5]. Hassan AA, Karzan AH (2013) Evaluation of trace elements in drinking water of Duhok Province/Kurdistan region of Iraq. IJESI 2: 47-56.

[6]. WHO (2011) Guidelines for drinking water quality. 4th Edition. World Health Organization, Geneva.

[7]. Gyamfi ET, Achah M, Anim AK, Hanson JK, Kpattah L, et al. (2012): Chemical analysis of potable water 
samples from selected suburbs of Accra., Ghana. Proc Int Acad Ecol Environ Sci 2: 118-127.

[8]. Al-Saleh, Al-Doush (1998) Survey of trace elements in household and bottled drinking water samples collected in Riyahd, Saudi Arabia. Sci Total Environ 216: 181-192.

[9]. Kumar SM , Gupta OP, Singh DK, Prasad AS (2014) Comparative physiochemical analysis of river water and underground water in winter season of Rewa town, MP, India. Int Res J Environment Sci 3: 59-61.

[10]. WHO (2004) Evaluation of certain food contaminants. 61st report of the Joint FAO/WHO Epert Committee on Food Additives. WHO Technical Report Series, No. 922. World Health Organization, Geneva.

[11]. ATSDR - Agency for Toxic Substances and Disease Registry (2008) Draft Toxicological profile for cadmium. United States Department of Health and Human Services, Public Health Human Services, Centre for Disease Control, Atlanta.

[12]. Khan AT (2011) Trace elements in Drinking Water and their Possible Health Effects in Aligarh City. J Water Resource and Prot 3: 522-530.

[13]. WHO (2006) Evaluation of certain food contaminants. 64th report of the Joint FAO/WHO Epert Committee on Food Additives. WHO Technical Report Series No. 930. World Health Organization, Geneva.

[14]. Apostoli P, Catalini S (2011) Metal ions affecting reproduction and development: Metal Ions in Life Sciences; Metal ions in Toxicology: Effects, Interactions, Interdependence. ISC Publishing 8.

[15]. Couto CM, Pinto I, Madureirea TV, Rocha MJ, Tiritan ME, et al. (2014) Lower Doureo river basin (Portugal) water quality-focus on trace element changes and anthropogenic sources of contamination. Glob NEST J 16: 252-268.

[16]. UNEP (2007) Global drinking water quality index, development and sensitivity analysis report.

[17]. Buschmann J, Berg M, Stengel C, Winkel L, Sampson ML, et al. (2008) Contamination of drinking water resources in the Mekong Delta flood plains; Arsenic and other trace metals pose serious health risks to the population. Environ Int 34: 756-764.

[18]. Sing S, Mosely LM (2003) Trace metals in drinking water in Viti Levu, Fiji Islands. S Pac J Nat Sci 21: 31-34.

[19]. Mudgal V, Madaan N, Mudgal A, Singh RB, Mishra S (2010) Effect of toxic metals on human health. Open Nutraceuticals J 3: 94-99.

[20]. Bolawa OE, Gbenle GO, Ebuehi OAT (2014) Endocrine disruption by the consumption of fish and its reversal using zinc. International Journal of Aquaculture 4: 85-88.

[21]. Bolawa OE, Gbenle GO (2013) Effect of the consumption of heavy metal contaminated fish on metabolic parameters in rabbits. IJABPT 4: 317-321.

[22]. Camacho LM, Gutierrez WM, Alarcon-Herrera MT (2011) Occurrence and treatment of arsenic in ground water and soil in Northern Mexico and South western USA. Chemosphere 83: 211-225.
[23]. Azizullah A, Khattak MNK, Richer P, Hader DP (2011) Water pollution in Pakistan and its impact on public health - A review. Environ Int 37: 479-497.

[24]. Mridul B, Prasad SH (2013) A GIS based assessment of $\mathrm{Pb}, \mathrm{As}, \mathrm{Cd}$ and $\mathrm{Al}$ contamination of ground water in Dhemaji district of Assam, India. Int J Res Chem Environ 3: 1-7.

[25]. Castro-Gonzalez M, Mendez-Armenta M (2008): Implications associated to food consumption. Environ Toxicol Pharmacol 26: 263-270.

[26]. Nwabueze AA (2010) Levels of some heavy metals in tissues of Bonga fish, Ethmalosa fimbriata from Forcadoes River. J Appl Environ Biol Sci 1: 44-47.

[27]. Ling MP, Hsu HT, Shie RH, Wu CC, M Hong YS (2009) Health risk of consuming heavy metals in farmed Tilapia in Central Taiwan. Bull Environ Contam Toxicol 83: 558-564.

[28]. Bolawa OE, Adelusi OS (2017) Determination of Heavy Metal Profile in Bottled Water and Sachet Water Samples Obtained From Various Markets in Lagos, Nigeria. Environ Pollut Climate Change 1: 114. 